ISSN: 2162-3104 Print/ ISSN: 2166-3750 Online

Volume 8, Issue 2 (2018), pp. 901-924

(C) Journal of International Students

http://jistudents.org/

doi: 10.5281/zenodo.1250391

\title{
The Effects of Cross-Cultural Competence and Social Support on International Students' Psychological Adjustment: Autonomy and Environmental Mastery
}

\author{
Norah Fahad Aldawsari \\ Valdosta State University, USA \\ Katharine S. Adams \\ Valdosta State University, USA \\ Lee Edmondson Grimes \\ Valdosta State University, USA \\ Steven Kohn \\ Valdosta State University, USA
}

\begin{abstract}
This study investigated relationships between cross-cultural competence, social support, and international students' psychological adjustment. Participants included 94 international students studying in the United States. The researchers conducted a series of standard multiple regression analysis to predict autonomy and environmental mastery as measured by the Ryff Scales of Psychological Well-Being (Ryff \& Keyes, 1995). They found significant positive relationships between autonomy and cross-cultural competence as measured by the Intercultural Competence Scale (ICCS; Fantini \& Tirmizi, 2006), and environmental mastery and social support as measured by the Multidimensional Scale of Perceived Social Support (MSPSS; Zimet, Dahlem, Zimet, \& Farely, 1988). A significant negative
\end{abstract}


relationship was also found between length of residency in the host country, autonomy, and environmental mastery.

Keywords: autonomy, cross-cultural competence, environmental mastery, international students, psychological adjustment, social support

The opportunity to study abroad provides an enriching academic and intercultural experience for international students. Study abroad is defined as an academic learning experience that takes place outside one's home country (Duke, Reinemund, \& Bouyer, 2014). Many international students choose to study abroad in the United States and worldwide. According to the Institute of International Education (IIE, 2017), approximately 1,078,822 international students from different countries attend colleges and universities within the United States. For many students, study abroad is an opportunity for personal growth and development (Kent-Wilkinson, Leurer, Luimes, Ferguson, \& Murray, 2015; McKeown, 2009; Twombly, Salisbury, Tumanut, \& Klute, 2012).

However, if students are not able to adjust to the demands of their new experience or cope effectively (Desa, Yusooff, \& Abd Kadir, 2012), their psychological well-being may be negatively impacted (Jackson, Ray, \& Bybell, 2013) resulting in depression, anxiety, physical complaints, stress and emotional exhaustion (Alzahem, Van der Molen, Alaujan, Schmidt, \& Zamakhshary, 2011; McGarvey, Brugh, Conroy, Clarke, \& Byrne, 2015; Sümer, Poyrazli, \& Grahame, 2008). Understanding key factors that influence the adjustment of international students is important for developing and maintaining a sense of well-being in the host country.

Given the importance of cross-cultural competence and social support in international students' adjustment (i.e., autonomy and environmental mastery), the primary goals of this research study were to answer the following questions:

1. What is the relationship between cross-cultural competence, social support, and autonomy?

2. What is the relationship between cross-cultural competence, social support, and environmental mastery? 


\section{LITERATURE REVIEW}

\section{Psychological Adjustment and Well-being}

Psychological well-being includes the ability to cope with environmental changes (Garcia, Al Nima, \& Kjell, 2014) and challenges encountered at various developmental stages (Ryff, 1989). Individuals that are well adjusted often report a greater sense of well-being in comparison to individuals with low levels of adjustment (Ordonez, Lima-Silva, \& Cachioni, 2011).

Ryff and Keyes (1995) provide a multidimensional approach to conceptualizing psychological well-being. The Ryff Scales of Psychological Well-Being measure various facets of adjustment including autonomy, environmental mastery, personal growth, positive relations with others, purpose in life, and self-acceptance (Bhullar, Hine, \& Phillips, 2014; Ryff \& Keyes, 1995). The two facets of adjustment that appear particularly relevant to the well-being of international students living in a host country are autonomy and environment mastery.

\section{Autonomy}

Autonomy is considered an essential psychological need central to healthy functioning (Ryan \& Deci, 2006) and overall well-being (Kasser \& Ryan, 1999). Scholars across disciplines have studied multiple types of autonomy. Kühler and Jelinek (2010) define personal autonomy as one's values, motivations, and moral standing that govern the individual's behavior free from the influence of others. Personal autonomy is a combination of self-directedness and self-government. On their measure of psychological well-being, Ryff and Keyes (1995) conceptualize autonomy as having confidence in one's opinions, even if they are contrary to the general consensus. The researcher used Ryff and Keyes' (1995) autonomy subscale in this study to measure international students' autonomy, an important aspect of psychological adjustment in the host country.

Previous research identified various internal factors that influence autonomy including general mood, emotion and attitudes; personality traits; stage of development; and age (Garcia \& Siddiqui, 2009; Kasser \& Ryan, 1999; Ryan \& Deci, 2006; Ryff, 1989). External factors, such as education (Kühler \& Jelinek, 2010), religious beliefs (Chirkov, 2014), socioeconomic status (Underlid, 2012), culture and diversity (Ryan \& Deci, 2006), and social support (Kasser \& Ryan, 1999; Lynch, 2013) also influence 
autonomy. Finally, cultural factors such as individualism and collectivism may be influential in that most individualistic societies value independence and collectivist societies discourage autonomous behaviors (Chirkov, 2014; McAuliffe, 2013; Ryan \& Deci, 2006).

\section{Environmental Mastery}

Environmental mastery is one's ability to either choose or create an environment that best fits his or her psychological state (Ryff \& Keyes, 1995). This ability to choose or create an environment that best supports one's psychological condition is also reflective of one's autonomy and provides one with a sense of control regarding the world he or she experiences (Wang, Nyutu, Tran, \& Spears, 2015). However, feeling that one's experiences are outside his or her control may prevent individuals from making small adaptive changes within the environment (Wang et al., 2015).

Similar to autonomy, both internal and external factors are associated with developing environmental mastery (Ryff, 1989). Internal factors include emotion/mood and personality (Poyrazli, Thukral, \& Duru, 2010; Ziskis, 2010), and age/maturity (Ryff \& Keyes, 1995). External factors such as education, travel, language development, cross cultural adaptation/competence, and social support also influence ones' level of environmental mastery (Bai, 2016; Chirkov, 2014; Garcia et al., 2014; Kim, 1992; Ryff, 1989; Sinicrope, Norris, \& Watanabe, 2007; Williams, 2005). Ryff (1989) pointed out that participating physically and mentally in different activities outside one's own environment affects one's level of environmental mastery and leads to advanced functioning in the world. The researcher used Ryff and Keyes' (1995) environmental mastery subscale in this study to measure international students' environmental mastery, another important aspect of psychological adjustment in the host country.

\section{Cross Cultural Competence}

By definition cross cultural competence emerges as a factor particularly relevant to the adjustment of international students in the host country. It reflects a combination of knowledge, attitudes, skills, and behaviors that international students acquire which facilitates their adjustment in the host country and allows them to focus more readily on their academic career. Several studies established significant relationships between autonomy and exposure to diverse cultures (Ryan \& Deci, 2006). 
Ryff (1989) explained that as individuals engage in different cultural experiences they engender a sense of freedom by expanding upon the norms that typically govern their behavior. Likewise, an individual's repeated interaction with and integration of the environment/culture leads to intercultural sensitivity, cross-cultural adaptation, and environmental mastery (Kim, 1993; Sinicrope et al., 2007).

Scholars have proposed various definitions of cross-cultural competence, but it is commonly conceptualized as a demonstration of knowledge, skills, and behaviors to function in diverse contexts (Cross, Bazron, Dennis, \& Isaacs, 1989; Leung, Ang, \& Tan, 2014; Sinicrope et al., 2007). The Intercultural Competence Scale (ICCS; Fantini \& Tirmizi, 2006) is consistent with common conceptualizations and utilizes four subscales to measure knowledge, attitudes, skills, and awareness. The researcher used the ICCS in this study to measure international student participants' crosscultural competence in the host country.

\section{Social Support}

Perceived social support is another influential factor to the adjustment of international students in the host country (Desa et al., 2012; Pham \& Saltmarsh, 2013). Social support refers to "the nature of the interactions occurring in social relationships, especially how these are evaluated by the person as to their supportiveness" (Mak \& Kim, 2011, p. $60)$.

Research indicates that having social support in the host country is important to the adjustment of international students for many reasons (Jackson et al., 2013; Mak \& Kim, 2011). Developing relationships with people in the host country helps international students learn about the host culture, norms, and expectations; experience less acculturative stress (Sullivan \& Kashubeck-West, 2015); successfully adjust to the new environment; and avoid negative psychological adjustment issues (Bai, 2016). These relationships also produce tolerance and empathy, important characteristics in adapting to the new environment (Garcia et al., 2014). International students with positive social support are less likely to report symptoms of anxiety/depression and stress, and this support helps them to adjust better to the cultural differences (Sümer et al., 2008; Jackson et al., 2013). Cultural characteristics of individualism and collectivism may also influence utilization of social support (Sawir, Marginson, Deumert, Nyland, \& Ramia, 2007). 
In relation to autonomy and environmental mastery, Ryan and Deci (2006) found that most individuals feel a sense of connectedness to people who support their autonomy. Kim (1992) found that intercultural communication promotes environmental mastery or "the individual's capacity to suspend or modify some of the old cultural ways to manage the dynamics of cultural difference/unfamiliarity, intergroup posture, and the accompanying stress" (p. 377). The researcher used the Multidimensional Scale of Perceived Social Support (MSPSS; Zimet et al., 1988) in the current study to measure international students' perceptions of important sources of social support (i.e., family, friends, or other significance) in the host country as it relates to autonomy and environmental mastery.

\section{METHOD}

\section{Participants}

The research sample included 167 international undergraduate and graduate students who were studying at colleges and universities in the Southeastern region of the United States. In the analysis of autonomy, 73 participants were excluded through list wise deletion and 94 participants were retained in the analysis. In the analysis of environmental mastery, 71 participants were excluded through list wise deletion and 96 participants were included in the analysis.

Table 1. Country of origin and gender of international students

\begin{tabular}{lccc}
\hline Country of Origin & $\begin{array}{c}\text { Total } \\
N=94\end{array}$ & $\begin{array}{c}\text { Female } \\
n=43\end{array}$ & $\begin{array}{c}\text { Male } \\
n=51\end{array}$ \\
\hline India & 23 & 9 & 14 \\
China & 20 & 11 & 9 \\
Saudi Arabia & 14 & 7 & 7 \\
Republic of Korea & 5 & 2 & 3 \\
Turkey & 3 & 0 & 3 \\
Iran & 3 & 1 & 2 \\
\hline
\end{tabular}

Note. Countries that contributed less than 3 participants to the analysis included Germany, Italy, Nepal, Mexico, Taiwan, Japan, Kuwait, Columbia, United Kingdom, Ecuador, Nigeria, Chile, Netherlands, Belize, Egypt, Bangladesh, Honduras, Brazil, Canada, and those participants that endorsed Rather Not Say. 
Missing data appeared random and no systematic patterns among missing values were identified. For both samples, age ranged from 18 to 38 years. The mean age of the original sample was $\mathrm{M}=24.68(\mathrm{SD}=4.27)$ as compared to $\mathrm{M}=25.15(\mathrm{SD}=4.24)$ of the retained sample. Age data was missing for 11 participants. Demographic characteristics including country of origin and gender for participants retained in the sample are presented in Table 1.

Of the 94 international student participants retained in the sample, 51 identified as being male $(54.30 \%)$, and 43 identified as being female $(45.70 \%)$. In terms of geographic region of origin, 31 participants $(33.00 \%)$ were from Northeast Asia (i.e., China, North Korea, South Korea, Indonesia, Nepal, and Japan); 23 were from South Asia - India (24.50\%); 22 were from the Middle East (23.40\%); 11 were from South America (11.70\%); three were from Europe (3.20\%); and one was from North America and Africa respectively $(1.1 \%)$. Two participants were missing geographic data $(2.10 \%)$. Finally, 85 participants $(90.40 \%)$ indicated that English was not their first language and nine participants $(9.60 \%)$ indicated that English was their first language.

When asked if being an international student was their first experience, 75 reported yes $(79.80 \%)$, and 19 reported no $(20.20 \%)$. When asked how long they had been in the host country, three reported one to three months $(3.20 \%)$; three reported four to six months $(3.20 \%)$; three reported between seven to nine months (3.20\%); eight reported between 10 to 12 months $(8.50 \%) ; 10$ reported more than one year $(10.60 \%) ; 65$ reported more than two years $(69.10 \%)$; and two reported "rather not to say" $(2.10 \%)$.

Regarding marital status, 72 participants identified as being single $(76.60 \%)$, 20 identified as being married $(21.30 \%)$, one identified as being widowed $(1.10 \%)$, and one identified as "rather not say" $(1.10 \%)$. When asked about their highest level of education, six indicated that they had a high school degree (6.40\%); 33 indicated that they had a bachelor's degree (35.10\%); 32 indicated that they had a master's degree $(34.00 \%) ; 21$ indicated that they had a doctoral degree (22.30\%); and two indicated their level of education as "other" $(2.10 \%)$.

\section{Procedure}

After Institutional Review Board (IRB) approval, the researcher recruited international students, age 18 and older, with the assistance of 
international student program offices at selected postsecondary institutions and student organizations within the Southeastern region of the United States. The researcher contacted program coordinators to request permission to send information about the research study and request participation from students through the program email and/or social media pages (e.g., Facebook and Instagram). Participation was completely voluntary. The goal of the research was to analyze aggregate data. No identifying information was collected, and participation remained anonymous. International students who agreed to participate accessed the online survey in Qualtrics with the provided URL.

Participants responded to the online survey and submitted the completed survey through Qualtrics. Participants completed the survey in approximately 25-30 minutes. International students who learned about the research opportunity and emailed the researcher were entered into a drawing for a chance to win a $\$ 50$ Amazon gift card. Students' names or email addresses were in no way associated with Qualtrics responses.

The researcher provided an informed consent statement to participants at the beginning of the online survey. The informed consent explained the purpose of the study, the procedures, and the potential benefits and possible risks of participation to student volunteers. Additionally, the statement informed participants of the voluntary nature of the study and that they could choose to not answer research questions or may discontinue participation at any time. The researcher explained to participants how to email her with questions or concerns regarding the research study.

\section{Measures}

The online survey included a demographic questionnaire, Ryff Scales of Psychological Well-Being (Ryff \& Keyes, 1995), Intercultural Competence Scale (ICCS; Fantini \& Tirmizi, 2006), and Multidimensional Scale of Perceived Social Support (MSPSS; Zimet at el., 1988). The demographic questionnaire was a self-report measure designed to obtain important information relevant to the study including age, gender, marital status, level of education, country of origin, length of stay in the host country, and whether English is their second language.

The Ryff Scales of Psychological Well-Being (Ryff \&Keyes, 1995) measure multiple facets of psychological well-being and adjustment including subjective, social, psychological, and health-related dimensions. The original scale has 54 items categorized into six subscales: autonomy, 
environmental mastery, personal growth, positive relations with others, purpose in life, and self-acceptance. Each subscale has nine items. The researcher used the autonomy and environmental mastery subscales in this study to measure the psychological well-being of international students as they adjust to the host country.

The autonomy subscale measured the degree to which international students' perceive themselves as independent and able to cope effectively with social pressure. Participants answered each question on a Likert scale from 1 (strongly disagree) to 6 (strongly agree). The researcher summed participant ratings for the subscale with scores ranging from 9 to 54. Low scores on the autonomy subscale indicate that participants have "concerns related to the expectation and evaluation of others, rely on the opinions of others to make important decisions, and conform to social pressure to think and act in a certain ways" (Ryff, 1989, p. 1072). High scores on the autonomy subscale indicate that participants are "self-determined and independent, able to resist social pressures to think and act in certain ways, regulate behavior from within, and use personal standards in selfevaluation" (Ryff, 1989, p. 1072). The autonomy subscale demonstrated high internal consistency and test-retest reliability $(.86, .88)$ in past research (Seifert, 2005). In the current study, the Cronbach's alpha coefficient for Autonomy ( 9 items; $\alpha=.74$ ) was acceptable.

The environmental mastery subscale measured international students' sense of mastery and competence in managing their environment. Participants answered each question on a Likert scale from 1 (strongly disagree) to 6 (strongly agree). The researcher summed participant ratings for the subscale with scores ranging from 9 to 54. Low scores on the environmental mastery subscale indicate that participants have "difficulty managing everyday affairs, feel unable to change or improve their surroundings, are unaware of surrounding opportunities, and lack a sense of control over their external world" (Ryff, 1989, p. 1072). High scores on environmental mastery subscale indicate that participants have "a sense of mastery and competence in managing the environment, control a complex array of external activities, make effective use of surrounding opportunities, (and) are able to create contexts suitable to their personal needs and values" (Ryff, 1989, p. 1072). The environmental mastery subscale demonstrated high internal consistency and test-retest reliability $(.90, .81)$ in past research (Seifert, 2005). In the current study, the Cronbach's alpha coefficient for Environmental Mastery ( 9 items; $\alpha=.73$ ) was acceptable. 
The Intercultural Competence Scale (ICCS; Fantini \& Tirmizi, 2006) is a measure of "complex abilities needed to perform effectively and appropriately when interacting with others who are linguistically and culturally different from oneself" (Fantini \& Tirmizi, 2006, p. 12). The 43item scale theoretically reflects the four components of cross-cultural experiences: knowledge (11 items), attitudes (10 items), skills ( 8 items), and awareness (14 items). Respondents rated statements on a Likert type scale from 0 (no competence) to 5 (strongly competent). The ICCS provides an overall score and four subscale scores. For this study, the researcher summed participant ratings across subscales to calculate a total score ranging from 0 to 215 . Low scores indicate that participants lack crosscultural competence and/or do not perform effectively in intercultural contexts. High scores indicate that participants are competent to function in cross-cultural contexts. The reliability of the ICCS as reported by Fantini and Tirmizi (2006) was .89. In the current study, the ICCS consisting of all 45 items had excellent internal consistency, $\alpha=.96$.

The Multidimensional Scale of Perceived Social Support (MSPSS; Zimet at el., 1988) is 12 items designed to measure perceptions of social support received from family, friends, and significant others. Participants rated each item on a Likert scale from 1 (very strongly disagree) to 7 (very strongly disagree). The MSPSS provides an overall score and three subscale scores. For this study, the researcher summed participant ratings across subscales to calculate a total score ranging from 12 to 84, with higher scores representing higher perceived social support and lower score representing lower perceived social support. The MSPSS has good reliability with coefficient alpha levels reported in past research between .84 to 92 (Zimet, Powell, Farley, Werkman, \& Berkoff, 1990). In the current study, the overall MSPSS consisting of 12 items had good reliability, $\alpha=.87$.

\section{Analysis}

The researcher conducted a series of standard multiple regression analysis to predict international students' autonomy and environmental mastery in the host country, the United States. Predictor variables included in the model were cross-cultural competence as measured by the ICCS, level of social support in the host country as measured by the MSPSS, geographic region of origin, gender, and length of residency in the host country. While the relationship between cross-cultural competence, social support and international student adjustment (i.e., autonomy and environmental mastery) 
was the primary focus of the study, the researcher included other variables shown to be influential in the literature to strengthen the overall predictive power of the model (Deng, Chang, Yang, Huo, Zhou, 2016; Hussain \& Munaf, 2012; Lee, Park, \& Kim, 2009; Mustaffa \& Ilias, 2013).

\section{RESULTS}

Preliminary analysis determined the proportion of missing data in the set was high but random. Analysis of data using mean substitution for missing data slightly increased the sample size but did not significantly impact the results as compared to analysis of data using list wise deletion. Therefore, to maintain the integrity of original data, the researcher opted to use list wise deletion and participants with missing values on the variables of interest were not included in the analysis. Additionally, one participant was identified as an outlier with a studentized residual above 3.0 and visual inspection of scatterplots and was removed from the sample. The researcher identified no serious violations of correct fit, constant variance, or normality assumptions. There was no reason to suspect violation of independence since none of the typical sources of violation of independence were present in this study.

Table 2. Variable coefficients predicting international students' autonomy

\begin{tabular}{lcccccccc}
\hline $\begin{array}{l}\text { Predictor } \\
\text { Variables }\end{array}$ & $M$ & $S D$ & $B$ & $\beta$ & $t$ & $p$ & $\begin{array}{c}\text { Bivariate } \\
r\end{array}$ & $\begin{array}{c}\text { Partial } \\
r\end{array}$ \\
\hline $\begin{array}{l}\text { Cross- } \\
\text { cultural } \\
\text { competence }\end{array}$ & 220.96 & 28.72 & 0.05 & $.21^{*}$ & 2.12 & .037 & .25 & .22 \\
$\begin{array}{l}\text { Social } \\
\text { support }\end{array}$ & 66.21 & 11.27 & 0.10 & .17 & 1.76 & .083 & .19 & .19 \\
$\begin{array}{l}\text { Geographic } \\
\text { region }\end{array}$ & & & 0.05 & .02 & 0.20 & .844 & .03 & .02 \\
$\begin{array}{l}\text { Length of } \\
\text { residency }\end{array}$ & & & & & & & & \\
Gender & & -1.36 & $-.28^{*}$ & -2.89 & .005 & -.30 & -.30 \\
& & & & & & & & \\
& & -1.51 & -.12 & -1.24 & .219 & -.15 & -.13 \\
\hline
\end{tabular}

*Significant at $\mathrm{p} \leq .05$ 


\section{Predicting Autonomy}

The model predicting participants' autonomy in the host country by cross-cultural competence, level of social support, geographic region of origin, gender, and length of residency in the host country was significant, $\mathrm{R} 2=.19, \mathrm{~F}(5,86)=4.00, \mathrm{p}=.003$. The effects of individual predictor variables on autonomy are summarized in Table 2 . Of the five predictor variables, only cross-cultural competence as measured by ICCS $(\beta=0.21), \mathrm{t}$ $=2.12, \mathrm{p}=.037$ and length of residency in the host country $(\beta=-0.28), \mathrm{t}=\mathrm{-}$ $2.89, \mathrm{p}=.005$ were significant. The data revealed that increased crosscultural competence was associated with increased international students' autonomy in the host country. Conversely, increased length of residency was associated with decreased international students' autonomy.

Table 3: Variable coefficients predicting international students' environmental mastery

\begin{tabular}{lcccccccc}
\hline $\begin{array}{l}\text { Predictor } \\
\text { Variables }\end{array}$ & $M$ & $S D$ & $B$ & $\beta$ & $t$ & $p$ & $\begin{array}{c}\text { Bivariate } \\
r\end{array}$ & $\begin{array}{c}\text { Partial } \\
r\end{array}$ \\
\hline $\begin{array}{l}\text { Cross- } \\
\text { cultural } \\
\text { competence }\end{array}$ & 220.43 & 28.65 & 0.03 & .14 & 1.51 & .136 & .20 & .16 \\
$\begin{array}{l}\text { Social } \\
\text { support }\end{array}$ & 66.19 & 11.21 & 0.18 & $.33^{*}$ & 3.51 & .001 & .36 & .35 \\
$\begin{array}{l}\text { Geographic } \\
\text { region }\end{array}$ & & & -0.19 & -.08 & -0.80 & .427 & -.04 & -.09 \\
$\begin{array}{l}\text { Length of } \\
\text { residency }\end{array}$ & & & & & & & & \\
& & -1.35 & $-.30 *$ & -3.20 & .002 & -.28 & -.32 \\
Gender & & & & & & & & \\
\hline
\end{tabular}

*Significant at $\mathrm{p} \leq .05$

\section{Predicting Environmental Mastery}

The model predicting international students' environmental mastery in the host country by cross-cultural competence, level of social support, geographic region of origin, gender, and length of residency in the host 
country was significant, $\mathrm{R} 2=.25, \mathrm{~F}(5,88)=5.71, \mathrm{p}<.001$. The effects of individual predictor variables on environmental mastery are summarized in Table 3. Of the five predictor variables, only social support as measured by the MSPSS $(\beta=0.33), t=3.51, p=.001$ and length of residency $(\beta=-0.30)$, $\mathrm{t}=-3.20, \mathrm{p}=.002$ were significant. The data revealed that increased level of social support in the host country was associated with increased international students' level of environmental mastery in the host country. Conversely, increased length of residency was associated with decreased level of environmental mastery.

\section{DISCUSSION}

An increase in the number of international students studying abroad has contributed to an increase in research related to this group and their adjustment process in the host country (Jourdini, 2012; Wu, Garza, \& Guzman, 2015). Among the 1.18 million total international students, approximately 290,836 new students, originating from 25 countries, studied in the United States in 2016 - 2017 (IIE, 2017). However, because international students come from varied cultural backgrounds, challenges may emerge from the acculturation process and/or lack of preparation (Duke et al., 2014). Individuals who encounter difficulties adapting to the host country may experience significant distress associated with psychological adjustment. While researchers have identified a number of internal and external factors influential in the adjustment process, the primary purpose of this study was to explore the relationship between cross-cultural competence and social support on international students' adjustment (i.e., autonomy and environmental mastery) in the host country. Based on a review of the literature, the researcher included in the model additional variables thought to be important in the prediction of international student adjustment. The final model, which significantly predicted both participants' autonomy and environmental mastery in the host country, included cross-cultural competence, level of social support, geographic region of origin, gender, and length of residency in the host country.

\section{Cross-cultural Competence and Social Support on Autonomy}

In the prediction of international student autonomy, cross-cultural competence contributed significantly to the prediction. Cross-cultural 
competence consists of the individual's knowledge, abilities, and skills required to adequately function and communicate effectively in a new culture (Wang, Freeman, \& Zhu, 2013). International students with high cross-cultural competence reported higher autonomy or a sense of independence and ability to resist social pressures in the host country. This finding was consistent with previous research which indicated that knowledge of cultural differences, including different groups of people, lifestyles, cultural values, habits, history and political issues plays a significant role in one's level of autonomy (Dekovic', Engels, Shirai, de Kort, \& Anker, 2002). This finding was also consistent with previous research (Czerwionka, Artamonova, \& Barbosa, 2014; Cicolini et al., 2015), indicating that prior experiences and exposure to diverse situations and people help to expand one's awareness in similar situations.

Social support did not significantly contribute to the prediction of student autonomy, perhaps in part because autonomy represents independence and self-directedness, and may not necessarily be associated with perceived social support from others. Additionally, past research indicates that perceived social support and autonomy may carry different meanings for international students from various cultures or different genders (Chirkov, 2007; Gurung, 2010; Ryff, 1989; Sawir et al., 2007; Tang, 2008). In the future, qualitative research or mix-method approaches are recommended to further explore how the constructs of autonomy and social support are defined among international students of various cultures and how such definitions may influence adjustment in the host country.

\section{Cross-Cultural Competence and Social Support on Environmental Mastery}

In the prediction of international student environmental mastery, social support contributed significantly. Findings indicate that social support in the form of relationships with one's family, old and new friends from the same or different ethnic or cultural group, and significant others (Şener, 2011) provide international students in the host country with a sense of control, the ability to act in the new environment, and to cope effectively with external challenges. These findings are consistent with previous research which concluded that international students with a strong relationship to individuals in the host country, regardless of their relationships within their cultural group, ultimately adjust to the host country and adapt to the differences better in comparison to those who do 
not have strong relationships within the host country (Mustaffa \& Ilias, 2013). International students may effectively acculturate through expanding meaningful social networks with their hosts (Mak \& Kim, 2011) while maintaining their identities and their social support from their own culture.

Surprisingly, cross-cultural competence did not contribute significantly to the prediction of environmental mastery within the current study, which is inconsistent with previous research (Berry, 2005). Current research focused exclusively on dynamic competencies (e.g., cultural skills, knowledge, behaviors), but there is research to suggest that adjustment is enhanced by both dynamic competencies and stable competencies (e.g., personality characteristics and traits) (Wang at el., 2013; Wu \& Bodigerel-Koehler, 2013). To explain such inconsistencies, future researchers may wish to distinguish between various types of cross-cultural competence in their research.

\section{Length of Residency and Adjustment}

Length of residence in the host country significantly contributed to the prediction of international student adjustment (both autonomy and environmental mastery). However, the negative correlation between length of residency and the variables of interest was unexpected. Findings indicate that international students who resided in the host country for longer periods of time reported lower levels of autonomy and environmental mastery. These results seem counterintuitive considering past research by Dwyer (2004) who found that longer study abroad periods are more beneficial than shorter programs in terms of understanding the culture, making friendships, gaining confidence, academic achievement and successful careers.

In interpreting these findings, it is important to consider the demographics of the sample. Well over half of the participants $(69.10 \%)$ reported living in the host country more than two years. It is plausible that the length of residency in the host country may be confounded by other internal or external factors that arose during the international students' study abroad. Additional longitudinal research is warranted to explore alternative explanations for findings, such as the acculturation process (Yakunina, Weigold, Weigold, Hercegovac, \& Elsayed, 2013), changes in social or political climate (Poyrazli \& Lopez, 2007), or changes in international student policies.

Additionally, future researchers may wish to investigate the potential impact of changes to the supports and services offered to students 
by international offices, faculty, and teachers. Many international students receive assistance and support from international offices and/or English as a Second Language (ESL) programs within the first year in the host country, but less support is provided as students transition into their academic program of study, which in turn may negatively impact their adjustment over time.

Finally, individuals may benefit from social support only if the type of support a person needs (e.g., emotional, esteem, instrumental, informational, and tangible support and social integration) matches the type of social support provided (Gurung, 2010; Tang, 2008). Future researchers may wish to investigate the type of support needed and received, the influence of assistance and supports, educational status (e.g., ESL student, undergraduate, or graduate), and/or level of self-efficacy. International students who stay longer in the host country may come to realize there is still much to be learned about their environment just as supports are being removed, which in turn could impact adjustment.

\section{Culture, Gender, and Adjustment}

Neither geographic region of origin nor gender contributed significantly to international student adjustment (i.e., autonomy and environmental mastery) in the current study. This is contrary to past research that found significant relationships between country of origin and the adjustment of international students (Mustaffa \& Ilias, 2013). Perhaps grouping participants into geographic regions did not account for the cultural differences that are often found between countries. It is also inconsistent with past research identifying relationships between gender and emotional instability (Hussain \& Munaf, 2012), cultural adjustment (Lee, Park, \& Kim, 2009), and emotional responses and experiences (Deng et al., 2016). Additional research is warranted in light of inconsistent research findings on cultural group and gender differences.

\section{Limitations}

Limitations with the current research involve the sample and region in which the study was conducted. While efforts were made to over sample, a substantial amount of missing data resulted in a small sample but with adequate power. The sample included international students from various countries studying at various universities, but as a whole they resided in the Southeastern region of the United States, and findings may not generalize to 
other areas of the United States. Additionally, because the psychological adjustment of international students may differ from one host country to another (Mustaffa \& Ilias, 2013), findings may not generalize to students hosted outside the United States. Future research may wish to conduct similar studies in other host countries.

Another plausible concern is that the study relied on online data collection and participant self-report. While unlikely, some participants included in the study may not truly represent the intended population. Also, self-reports potentially could be biased or represent diverse cultural perspectives. The researcher made efforts to examine the influence of diverse cultural perspectives and no significant relationships were found. Nevertheless, as with all research, results should be interpreted in light of possible cultural limitations.

\section{CONCLUSION}

Knowing key factors that influence the autonomy and environmental mastery of international students is important to international students and those who strive to enhance their adjustment in the host country. The current research may help international students, their parents, and those who work with international students (e.g., study abroad programs, international studies, international organizations, English institutions, ESL teachers, professors, international students' advisors, and/or those who are interested in cultural diversity) to identify key factors influential to successful adjustment in the host country.

Efforts to develop students' cross-cultural competence and social support may begin well before their departure for the host country. Students may benefit from models of multicultural curiosity, friendships with others from different cultures, and if feasible, travel. Additionally, while still in their home country, students may be encouraged to participate in cultural diversity classes at their schools and/or university, engage in cross-cultural activities (i.e., presentations, events, or festivals), and/or work to establish international networks. Such efforts should continue also after an international students' arrival in the host country. International students should be encouraged to maintain relationships in their home country as well as to develop their social support networks in the host country. While social media is a valuable tool often used in maintaining a sense of connectedness with friends and family in the home country, it is important 
also to encourage students to venture into their new environments to develop relationships with those in the host country. Students would benefit from programs sponsored by academic institutions that provide opportunities for them to practice their developing language skills, bolster social support in the host country, and increase cross-cultural competence. Academic institutions also could provide enrichment opportunities for faculty and staff to learn more about international students and their unique challenges, and offer culturally sensitive counseling services that provide assistance in alleviating adjustment difficulties.

The number of international undergraduate and graduate students hosted in the United States has increased consistently over the past 10 years (Redden, 2016) illustrating the importance of supporting international student adjustment. There is a need for more international student research that identifies internal and external factors influential to psychological adjustment as well as programs designed to facilitate the adjustment of international students in the host country. Such research and/or programs will not only benefit international students, their parents, and those who work directly with international students, but also may contribute to promoting international studies across home and host countries.

\section{REFERENCES}

Alzahem, A. M., Van der Molen, H. T., Alaujan, A. H., Schmidt, H. G., \& Zamakhshary, M. H. (2011). Stress amongst dental students: A systematic review. European Journal of Dental Education, 15(1), 8-18. doi:10.1111/j.1600-0579.2010.00640.x

Bai, J. (2016). Perceived support as a predictor of acculturative stress among international students in the United States. Journal of International Students, 6(1), 93-106. Retrieved from http://files.eric.ed.gov/ fulltext/EJ1083271.pdf

Berry, J. W. (2005). Acculturation: Living successfully in two cultures. International Journal of Intercultural Relations, 29(6), 697-712. doi:10.1016/j.ijintrel.2005.07.013

Bhullar, N., Hine, D. W., \& Phillips, W. J. (2014). Profiles of psychological wellbeing in a sample of Australian university students. International Journal of Psychology, 49(4), 288-294. doi:10.1002/ijop.12022

Chirkov, V. I. (2014). The universality of psychological autonomy across cultures: Arguments from developmental and social psychology. In N. Weinstein (Ed.), Human Motivation and Interpersonal Relationships: Theory, Research, and Applications (pp. 27-52). Dordrecht, NL: Springer. 
Retrieved from http://www.springer.com/cda/content/document/cda downloaddocument/9789401785419-c2.pdf?SGWID=0-0-45-1492245p176370416

Chirkov, V.I. (2007). Culture, personal autonomy and individualism: their relationships and implications for personal growth and well-being. In G. Zheng \& K. Leung \& J. G. Adair (Eds.), Perspectives and Progress in Contemporary Cross-Cultural Psychology (pp. 247-263). Beijing, China: China Light Industry Press. Retrieved from http://iaccp.org/ ebook/xian/PDFs/5 1Chirkov.pdf

Cicolini, G., Della Pelle, C., Comparcini, D., Tomietto, M., Cerratti, F., Schim, S. M., Giovanni, P. D., \& Simonetti, V. (2015). Cultural competence among Italian nurses: A multicentric survey. Journal of Nursing Scholarship, 47(6), 536-543. doi:10.1111/jnu. 12165

Cross, T. L., Bazron B. J., Dennis K. W., \& Isaacs M. R. (1989). Towards a culturally competent system of care: Vol. I. Washington, DC: National Technical Assistance Center for Children's Mental Health, Georgetown University Child Development Center. Retrieved from http://files.eric. ed.gov/fulltext/ED330171.pdf

Czerwionka, L., Artamonova, T., \& Barbosa, M. (2014). Intercultural competence during short-term study abroad: A focus on knowledge. Proceedings of the Intercultural Competence Conference, 3, 46-77. Retrieved from http://cercll.arizona.edu/_media/development/conferences/2014_icc/icc14p roceedings_czerwionka_artamonova_barbosa_icc_study_abroad.pdf

Dekovic', M., Engels, R. C. M. E., Shirai, T., de Kort, G., \& Anker, A. L. (2002). The role of peer relations in adolescent development in two cultures: The Netherlands and Japan. Journal of Cross-Cultural Psychology, 33(6), 577595. doi:10.1177/022022102238270

Deng, Y., Chang, L., Yang, M., Huo, M., \& Zhou, R. (2016). Gender differences in emotional response: Inconsistency between experience and expressivity. Plos ONE, 11(6), 1-12. doi:10.1371/journal.pone.0158666

Desa, A., Yusooff, F., \& Abd Kadir, N. B. (2012). Acculturative stress among international postgraduate students at UKM. Procedia - Social and Behavioral Sciences, 59, 364-369. doi: 10.1016/j.sbspro.2012.09.287

Duke, S. T., Reinemund, S. S., \& Bouyer, K. (2014). Preparing to Study Abroad: Learning to Cross Cultures. Sterling, Virginia: Stylus.

Dwyer, M. M. (2004). More is better: The impact of study abroad program duration. The Interdisciplinary Journal of Study Abroad, 10, 151-163. Retrieved from http://files.eric.ed.gov/fulltext/EJ891454.pdf

Fantini, A., \& Tirmizi, A. (2006). Exploring and assessing intercultural competence. World Learning Publications. Paper 1. Retrieved from $\mathrm{http} / /$ digitalcollections.sit.edu/worldlearning_publications/1 
Garcia, D., Al Nima, A., \& Kjell, O. N. E. (2014). The affective profiles, psychological well-being, and harmony: Environmental mastery and selfacceptance predict the sense of a harmonious life. Peerj, 2(e259), 1-2. doi:10.7717/peerj. 259

Garcia. D., \& Siddiqui, A. (2009). Adolescents' psychological well-being and memory for life events: Influences on life satisfaction with respect to temperamental dispositions. Journal of Happiness Studies, 10(4), 407-419. doi: 10.1007/s10902-008-9096-3

Gurung, R. A. R. (2010). Health Psychology: A Cultural Approach. Belmont, CA: Wadsworth.

Hussain, S., \& Munaf, S. (2012). Gender difference in perceived childhood father rejection and psychological adjustment in adulthood. Journal of Behavioural Sciences, 22(1), 100-114. Retrieved from http://eds.b.ebscohost.com/eds/pdfviewer/pdfviewer?vid $=5 \&$ sid=f93cdfeb7950-4faf-a6e8-8154820c10db\%40sessionmgr105\&hid=103.

Institute of International Education (IIE). (2017). International student enrollment trends, 1948/49-2016/17. Open Doors Report on International Educational Exchange. Retrieved from http://www.iie.org/opendoors.

Jackson, M., Ray, S., \& Bybell, D. (2013). International students in the U.S.: Social and psychological adjustment. Journal of International Students, 3(1), 1728. Retrieved from http://files.eric.ed.gov/fulltext/EJ1056438.pdf

Jourdini, M. M. (2012).The impact of international students on American Students and faculty at an Appalachian university. Online Theses and Dissertations. Paper 107. Retrieved from http://encompass.eku.edu/cgi/viewcontent. cgi?article $=1106 \&$ context $=$ etd

Kasser, V. G., \& Ryan, R. M. (1999). The relation of psychological needs for autonomy and relatedness to vitality, well-being, and mortality in a nursing home. Journal of Applied Social Psychology, 29(5), 935-954. doi:10.1111/j.1559-1816.1999.tb00133.x

Kent-Wilkinson, A., Dietrich Leurer, M., Luimes, J., Ferguson, L., \& Murray, L. (2015). Studying abroad: Exploring factors influencing nursing students' decisions to apply for clinical placements in international settings. Nurse Education Today, 35, 941-947. doi:10.1016/j.nedt.2015.03.012

Kim, Y. K. (1993). Cross-cultural adaptation: An integrative theory. In R. L. Wiseman \& J. Koester (Eds.), Intercultural Communication Theory (pp. 170-193). Newbury Park, CA: Sage.

Kim, Y.Y. (1992). Intercultural communication competence: A systems-thinking view. In Gudykunst, W. B. \& Kim, Y. Y. (Eds.), Readings on Communicating with Strangers: An Approach to Intercultural Communication (pp. 371-381). New York: McGraw-Hill.

Kühler, M., \& Jelinek, N. (2010). Autonomy and self. Preprints of the Centre for Advanced Study in Bioethics. Retrieved from https://www.uni- 
muenster.de/imperia/md/content/kfg-normenbegruendung/intern/ publikationen/kuehler/10_k hler_-_autonomy_and the_self.pdf

Lee, S. A., Park, H. S., \& Kim, W. (2009). Gender differences in international students' adjustment. College Student Journal, 43(4), 1217-1227. Retrieved from http://eds.a.ebscohost.com/eds/detail/detail?vid=5\&sid=7b42bf8c4069-41e0-b54c-2d8f31426a10\%40sessionmgr4009\&hid=4102\&bdata $=$ JnNpdGU9ZWRzLWxpdmUmc2NvcGU9c210ZQ\%3d\%3d\#AN=483186 $44 \& \mathrm{db}=\mathrm{tfh}$

Leung, K., Ang, S., \& Tan, M. L. (2014). Intercultural Competence. Annual Review of Organizational Psychology and Organizational Behavior, 1, 489-519. doi: 10.1146/annurev-orgpsych-031413-091229

Lynch, M. F. (2013). Attachment, autonomy, and emotional reliance: A multilevel model. Journal of Counseling \& Development, 91(3), 301-312. doi:10.1002/j.1556-6676.2013.00098.x

Mak, A. S., \& Kim, I. (2011). Korean international students' coping resources and psychological adjustment in Australia. The Journal of Multicultural Society, 2(1), 56-84. Retrieved from http://www.omnesjournal.org/ upload/public/pdffile/10/2.pdf

McAuliffe, G. (2013). Culturally Alert Counseling: A Comprehensive Introduction. Thousand Oaks, CA: SAGE.

McGarvey, A., Brugha, R., Conroy, R. M., Clarke, E., \& Byrne, E. (2015). International students' experience of a western medical school: a mixed methods study exploring the early years in the context of cultural and social adjustment compared to students from the host country. BMC Medical Education, 15(111), 1-13. doi:10.1186/s12909-015-0394-2

McKeown, J. S. (2009). The first time effect: The impact of study abroad on college student intellectual development. Retrieved from http://eds.b.ebscohost. com/eds/ebookviewer/ebook/bmxlYmtfXzI2NTkwNV9fQU41?sid=00c92 4ee-e46a-4de9-8bfe40be38864ee8@sessionmgr102\&vid=0\&format=EB\&rid=1

Mustaffa, C. S., \& Ilias, M. (2013). Relationship between students' adjustment factors and cross-cultural adjustment: A survey at the northern university of Malaysia. Intercultural Communication Studies, 22(1), 279-300. Retrieved from http://eds.a.ebscohost.com/eds/pdfviewer/pdfviewer?sid= 796caf51-74a4-40d3-a015$32 \mathrm{da} 36322810 \% 40$ sessionmgr4008\& vid $=82 \& \mathrm{hid}=4111$

Ordonez, T. N., Lima-Silva, T. B., \& Cachioni, M. (2011). Subjective and psychological well-being of students of a university of the third age: Benefits of continuing education for psychological adjustment in the elderly. Dementia \& Neuropsychologia, 5(3), 216-225. doi: 10.1590/S1980-57642011DN05030010 
Pham, L., \& Saltmarsh, D. (2013). International students' identities in a globalized world: Narratives from Vietnam. Journal of Research in International Education, 12(2), 129-141. doi:10.1177/1475240913481171

Poyrazli, S., \& Lopez, M. D. (2007). An exploratory study of perceived discrimination and homesickness: A comparison of international students and American students. The Journal of Psychology, 141(3), 263-280. doi: 10.3200/JRLP.141.3.263-280

Poyrazli, S., Thukral, R. K., \& Duru, E. (2010). International students' raceethnicity, personality and acculturative stress. Journal of Psychology and Counseling, 2(8), 25-32. Retrieved from http://www.academicjournals.org/ article/article1380360045_Poyrazlit\%20al.pdf

Redden, E. (2016). International student numbers top 1 million. Inside Higher Ed. Retrieved from https://www.insidehighered.com/news/2016/11/14/annualopen-doors-report-documents-continued-growth-international-students-usand-us.

Ryan, R. M., \& Deci, E. L. (2006). Self-regulation and the problem of human autonomy: Does psychology need choice, self-determination, and will? Journal of Personality, 74(6), 1557-1586. doi:10.1111/j.14676494.2006.00420.x

Ryff, C. D. (1989). Happiness is everything, or is it? Explorations on the meaning of psychological well-being. Journal of Personality and Social Psychology, 57(6), 1069-108. doi:10.1037/0022-3514.57.6.1069

Ryff, C., \& Keyes, C. (1995). The structure of psychological well-being revisited. Journal of Personality and Social Psychology, 69,719-727.Reterivered from http://midus.wisc.edu/findings/pdfs/830.pdf

Sawir, E., Marginson, S., Deumert, A., Nyland, C., \& Ramia, G. (2007). Loneliness and international students: An Australian study. Journal of Studies in International Education, 12(2), 148-180. doi: 10.1177/1028315307299699

Seifert, T. A. (2005). The Ryff scales of psychological well-being. Retrieved from http://www.liberalarts.wabash.edu/ryff-scales/

Şener, A. (2011). Emotional support exchange and life satisfaction. International Journal of Humanities and Social Science, 1(2), 79-88. Retrieved from http://www.ijhssnet.com/journals/Vol._1_No._2;_February_2011/10.pdf

Sinicrope, C., Norris, J., \&Watanabe, Y. (2007). Understanding and assessing intercultural competence: A summary of theory, research, and practice (technical report for the foreign language program evaluation project). Second Language Studies, 26(1), 1-58. Retrieved from http://www.hawaii.edu/sls/wp-content/uploads/2014/09/Norris.pdf

Sullivan, C., \& Kashubeck-West, S. (2015). The interplay of international students' acculturative stress, social support, and acculturation modes. Journal of International Students, 5(1), 1-11. Retrieved from http://files.eric. ed.gov/fulltext/EJ1052843.pdf 
Sümer, S., Poyrazli, S., \& Grahame, K. (2008). Predictors of depression and anxiety among international students. Journal of Counseling \& Development, 86(4), 429-437. doi: 10.1002/j.1556-6678.2008.tb00531.x

Tang, Y. (2008). Social support of elderly caregivers. International Journal of Business and Management, 3(8), 81-84. Retrieved from http://www.ccsenet.org/journal/index.php/ijbm/article/viewFile/1314/1275

Twombly, S.B., Salisbury, M. H., Tumanut, S. D., \& Klute. P. (2012). J-B ASHE Higher Education Report Series (AEHE): Study abroad in a new global century: Renewing the promise, refining the purpose, ASHE Higher Education Report (1). Somerset, US: Jossey-Bass. Retrieved from http://site.ebrary.com.library.valdosta.edu:2048/lib/valdosta/reader.action? $\operatorname{doc} \mathrm{ID}=10618829$

Underlid, K. (2012). Autonomy and poverty - An empirical study of long-term recipients of social assistance. Social Welfare. doi: 10.5772/37833

Wang, D., Freeman, S., \& Zhu, C. J. (2013). Personality traits and cross-cultural competence of Chinese expatriate managers: a socio-analytic and institutional perspective. International Journal of Human Resource Management, 24(20), 3812-3830. doi:10.1080/09585192.2013.778314

Wang, M-C., Nyutu, P. N., Tran, K. K., Spears, A. (2015). Finding resilience: The mediation effect of sense of community on the psychological well-being of military spouses. Journal of Mental Health Counseling, 37(2), 164-174. doi:10.17744/mehc.37.2.07054x614489204m

Williams, T. R. (2005). Exploring the impact of study abroad on students' intercultural communication skills: Adaptability and sensitivity. Journal of Studies in International Education, 9(4), 356-371. doi: $10.1177 / 1028315305277681$

Wu, H., Garza, E., \& Guzman, N. (2015). International student's challenge and adjustment to college. Education Research International, 20151. doi: $10.1155 / 2015 / 202753$

Wu, W., \& Bodigerel-Koehler, M. (2013). The mediating effects of cross-cultural dynamic competencies on the relationship between multicultural personality and cross-cultural adjustment. International Journal of Human Resource Management, 24(21), 4026-4045. doi:10.1080/ 09585192.2013.781518

Yakunina, E. S., Weigold, I. K., Weigold, A., Hercegovac, S., \& Elsayed, N. (2013). International students' personal and multicultural strengths: Reducing acculturative stress and promoting adjustment. Journal of Counseling \& Development, 91(2), 216-223. doi: 10.1002/j.15566676.2013.00088.x

Zimet, G. D., Dahlem, N. W., Zimet, S. G. \& Farley, G. K. (1988). The multidimensional scale of perceived social support. Journal of Personality Assessment, 52(1), 30-41. doi: 10.1207/s15327752jpa5201_2 
Zimet, G. D., Powell, S. S., Farley, G. K., Werkman, S., \& Berkoff, K. A. (1990). Psychometric characteristics of the Multidimensional Scale of Perceived Social Support. Journal of Personality Assessment, 55(3-4), 610-617. doi: $10.1080 / 00223891.1990 .9674095$

Ziskis, A. S. (2010). The relationship between personality, gratitude, and psychological well-being (Doctoral dissertation, New Bruncwick Rutgers, State University of New Jersey). Retrieved from http://www.libraries.rutgers.edu/

NORAH FAHAD ALDAWSARI, MS, is a graduate of the Department of Psychology, Counseling, and Family Therapy at Valdosta State University, United States. Her research interests include the adjustment and academic success of international students. Email: norah.aldawsari@gmail.com

KATHARINE S. ADAMS, $\mathrm{PhD}$, is an Associate Professor in the Department of Psychology, Counseling, and Family Therapy at Valdosta State University, United States. Her research interests include the socialemotional adjustment and academic success of both high and low achieving students as well as the social stigma associated with disability. Email: ksadams@valdosta.edu

LEE EDMONDSON GRIMES, PhD, is an Associate Professor in the Department of Psychology, Counseling, and Family Therapy at Valdosta State University, United States. Her research interests include rural education including the practices of rural school counselors to meet student, family, and community needs through STEM career awareness and social justice advocacy. Email: legrimes@valdosta.edu

STEVEN KOHN, PhD, is an Associate Professor in the Department of Psychology, Counseling, and Family Therapy at Valdosta State University, United States. His research interests include stress, coping, and well-being across the life-span, the psychology of aging, and applied cross-national research.Email: sjkohn@valdosta.edu

Manuscript submitted: May 23, 2017

Revised version receive: August 10, 2017 Accepted for publication: December 19, 2017 